\title{
IM GEDENKEN AN IMRE MOLNÁR
}

\section{September 1934 - 16. Oktober 2016}

Am 16. Oktober 2016 ist Professor Imre Molnár, der international anerkannte Romanist und hochgeschätzte Lehrer und Meister von ungarischer Juristengenerationen dahingeschieden.

Imre Molnár ist am 22. September 1934 in Tataháza geboren. Seine Gymnasialstudien absolvierte er in Baja und Szeged. Bereits zu dieser Zeit wurde sein Interesse - vor allem von seinem Lateinlehrer József Visy - für die klassische Antiquität geweckt. Sein Universitätsstudium durfte er erst im Revolutionsjahr 1956 beginnen, da er aufgrund seiner Abstammung (um die damalige Terminologie des Kommunismus zu gebrauchen) als „klassenfremd“ galt. Sein Diplom erwarb er im Jahre 1960 an der Universität der Wissenschaften in Szeged. Während seines Jurastudiums erwachte sein Interesse für das römische Recht, vor allem dank seinem Meister Professor Elemér Pólay (1915-1988), dem wahrscheinlich bedeutendsten Romanisten seiner Zeit.

Nach seinem Studium ging er in die juristische Praxis und kehrte nach acht Jahren (in 1968) dem Ruf von Professor Pólay folgend an die Universität in Szeged zunächst als Assistent zurück, wo er in 1979 (nach dem Erwerb des Titels Candidatus Scientiarum, d.h. nach seiner Promotion) zum Dozenten ernannt wurde. Im Jahre 1985 übernahm er die Leitung des Lehrstuhls für römisches Recht (die er bis 1999, d.h. bis zu seinem 65. Lebensjahr innehatte) von Professor Pólay, den er nicht nur als seinen Meister verehrte, sondern ihm auch freundschaftlich bis an dessen Lebensende nahestand. In 1987 erwarb er den Titel Doctor Scientiarum (in der heutigen Terminologie: Doktor der Ungarischen Akademie der Wissenschaften) und wurde in darauf folgenden Jahr zum Universitätsprofessor ernannt. Von 1994 
bis 1998 stand er als Dekan der Staats- und Rechtswissenschaftlichen Fakultät der Universität in Szeged (damals József Attila Universität der Wissenschaften) vor. Im Jahre 2004 ging er in den Ruhestand und wurde emeritiert. Während seiner ganzen Laufbahn hielt er regelmäßig Vorträge an internationalen Konferenzen und seine längere Forschungsaufenthalte in München, Rom und Köln ermöglichten es ihm wissenschaftliche und freundschaftliche Bande mit den bedeutendsten Romanisten seiner Generation zu knüpfen.

Die Schwerpunkte seiner Forschungsarbeit lagen in drei Themenkreisen: der locatio conductio, der Haftungsordnung des römischen Rechts und des römischen Strafrechts. Seine - in 1977 verteidigte - Promotionsarbeit ist im Jahre 1982 auf Ungarisch erschienen ${ }^{1}$ und noch im selben Jahr veröffentliche er im Aufstieg und Niedergang des römischen Welt einen längeren Beitrag über die „Verantwortung und Gefahrtragung bei der locatio conductio zur Zeit des Prinzipats“. ${ }^{2}$ Über die Jahrzehnte publizierte er mehrere Arbeiten über die verschiedenen Aspekte der locatio conductio. ${ }^{3}$ Den Titel Doctor Scientiarum erlangte er im Jahre 1987 mit seiner Arbeit über die Haftungsordnung des römischen Rechts, ${ }^{4}$ die in 1993 auf Ungarisch und in 1998 auch auf Deutsch veröffentlicht wurde. ${ }^{5}$ Über die verschiedenen Aspekte desselben Themas publizierte er zahlreiche weitere Beiträge in Ungarn und im Ausland, ${ }^{6}$ die ihn zu einem der anerkanntesten Experten dieses (im römischen Recht

1 „A locatio conductio a klasszikus kori római jogban“ [„Die locatio conductio im klassischen römischen Recht“] Acta Universitatis Szegediensis, Acta Juridica et Politica Tom XXIX 198296 S (Zweite erweiterte Auflage (Szeged) 2013: 197 S).

2 In Aufstieg und Niedergang des römischen Welt Teil II Band 14 (Berlin-New York) 1982: 583680 .

3 „Gefahrtragung beim römischen Dienst und Werkvertrag“ Labeo 1975: 23-44; „Subjekte der locatio conductio" in Studi in onore di Cesare Sanfilippo II (Milano) 1982: 413-430; „Objekt of locatio conductio" in Bullettino dell' Istituto di Diritto Romano 1982: 127-142; "The social determination of lease relations and the social programs arising from that in Ancient Rome" in Studia in Honorem L. Nagy. (Acta Universitatis Szegediensis, Acta Juridica et Politica Tom XXXI) (Szeged) 1984: 223-229; ,Rechte und Pflichten der Subjekte der locatio conductio“ Index 1983-1984: 157-188; Le cause di estinzione del contratto e il problema dell' esistenza del diritto di disdetta nella „locatio-conductio” Labeo 1986: 298-309; „Beruf und Arbeit im römischen Recht in Facetten des Wandels" (Mannheim) 2001: 54-62.

4 A római magánjog felelösségi rendje [Die Haftungsordnung des römischen Privatrechts] (Szeged) 1993: $252 \mathrm{~S}$.

5 Die Haftungsordnung des römischen Privatrechts (1998) (Szeged) $216 \mathrm{~S}$.

6 „Die Ausgestaltung des Begriffes der vis maior im römischen Recht“ IURA 1981: 73-105; „Erfolgshaftung oder ein typisierter dolus malus im archaischen römischen Recht“ Bullettino dell' Istituto di Diritto Romano 1987: 27-43; „Der Haftungsmaßstab des pater familias diligens im römischen Recht" in Vorträge gehalten auf dem 28. Deutschen Rechtshistorikertag (Nimwegen 23. bis 27. September 1990) (Nijmegen) 1992: 23-31; „Die Haftungsordnung des römischen Privatrechts“ Acta Universitatis Szegediensis, Acta Juridica et Politica Tom XLIX (Szeged) 1996: 371-383. 
zentralen) Fragekreises machten. In den letzten zwei Jahrzehnten seines Lebens galt sein Interesse in erster Linie dem römischen Strafrecht: mehrere seiner Arbeiten sind auch in deutscher Sprache veröffentlicht worden, ${ }^{7}$ und im Jahre 2013 wurde ein Sammelband seiner Aufsätze, die diesem Thema galten, herausgegeben. ${ }^{8}$ Neben diesen größeren Themenkreisen behandelte er zahlreiche weitere Fragen in seinen Beiträgen, so unter anderen die Problematik der Gefahrtragung beim Kauf. ${ }^{9}$

Sein Lebenswerk wurde er mit zahlreichen Preisen und Ehrungen bedacht: In 1999 erhielt er den Apácai Csere János Preis, in 1995 und 2004 wurde er von seinen Studenten zum Lehrer des Jahres gewählt, in 2003 erhielt er den Offizierskreuz des Verdienstordens der Ungarischen Republik, in 2005 den Klebersberg Kúnó Preis und in 2007 den Eötvös József Kranz; anlässlich seines 70., 75. und 80. Geburtstages wurde er von seinen Schülern und Kollegen mit Festschriften beehrt. ${ }^{10}$

Das Hinterland für seine ertragreiche Forschungs- und Lehrarbeit bot sein - einem bonus et diligens pater familias würdiges - Privatleben: im Jahre 1960 heiratete er die Gymnasiallehrerin Magdolna Asztalos; seine Tochter Judit ist Richterin, sein Sohn Attila Anwalt geworden. Zeit seines Lebens war er ein nicht nur geistig, sondern auch körperlich aktiver Mensch: der Liebe zum Sport (in den 70er Jahren gewann er mit seiner Mannschaft die Goldmedaille des Ungarischen Athletischen Turniers in Hammerwurf) und zur Gartenarbeit blieb er bis ins hohe Alter treu.

Während der Zeit seiner Lehrtätigkeit, die sich fast über ein halbes Jahrhundert erstreckt hatte, ist es ihm - dank seiner eruditio und didaktischem Gefühl - gelungen seinen Studenten das römische Recht auf jener Weise nahezubringen, die nicht nur

7 "Grundprinzipien des römischen Strafrechts“ in A bonis bona discere: Festgabe für János Zlinszky zum 70. Geburtstag (Miskolc) 1998: 189-208; „Das adulterium als ein das Ansehen der römischen Familie verletzendes Verbrechen“ in Status familiae. Festschrift für Andreas Wacke zum 65. Geburtstag (München) 2001: 345-364; „Ausgewählte gesetzliche Straftatbestände im antiken Rom und in unserem geltendem Recht" in Roman Law as Formative of Modern Legal Systems. Studies in Honour of Wieslaw Litewski (Kraków) 2004: 15-24.

8 Ius criminale Romanum (Szeged) 2013: $255 \mathrm{~S}$.

9 „Periculum emptoris im römischen Recht der klassischen Periode“ in Sodalitas. Scritti in onore di Antonio Guarino (Napoli) 1984: 2227-2255; „Die Frage der Gefahrtragung und des Eigentumsüberganges beim Kauf"Index 1987: 57-75.

10 „Tanulmányok Molnár Imre tiszteletére [Beiträge zu Ehren von Imre Molnár]“ Acta Universitatis Szegediensis, Acta Juridica et Politica Tom LXV (Szeged) 2004: 842 S; Római jog és a magánjog fejlödése Európában. Tanulmányok Molnár Imre 75. születésnapjára [Römisches Recht und Privatrechtsentwicklung in Europa. Beiträge zu Ehren des 75. Geburtstages von Imre Molnár] (Szeged) 2011: 264 S; „Ünnepi kötet Dr. Molnár Imre egyetemi tanár 80. születésnapjára“ Festschrift zu Ehren des 80. Geburtstages von Imre Molnár. Acta Universitatis Szegediensis, Acta Juridica et Politica Tom LXXVI (Szeged) 2014: 516 S. 
für die wissenschaftliche Bildung, sondern auch für das pragmatische Rechtsdenken von Juristengenerationen von ausschlaggebender Bedeutung war.

Mit dem Ableben von Imre Molnár - eines Meisters und Freundes, der seinen Schülern und Kollegen jederzeit mit Rat und Tat beizustehen bereit war - ist auch der letzte Vertreter jener großen Generation der ungarischen Romanistik, zu der György Diósdi (1934-1973), Ferenc Benedek (1926-2007) und János Zlinszky (1928-2015) gehörte, dahingeschieden.

Sit ei terra levis!

Tamás Nótári

Wissenschaftlicher Hauptmitarbeiter des Rechtswissenschaftlichen Instituts des Zentrums für Gesellschaftswissenschaften der Ungarischen Akademie der

Wissenschaften; Universitätsdozent der Sapientia Ungarischen Universität in Transsylvanien 